
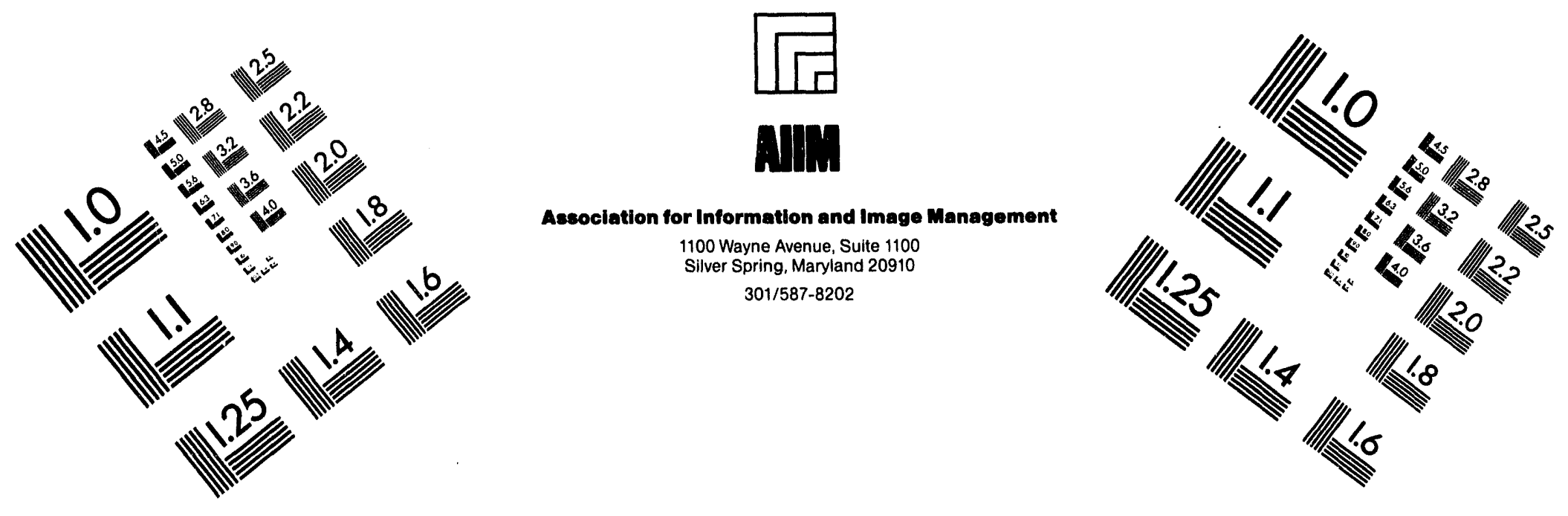

\title{
Centimeter
}

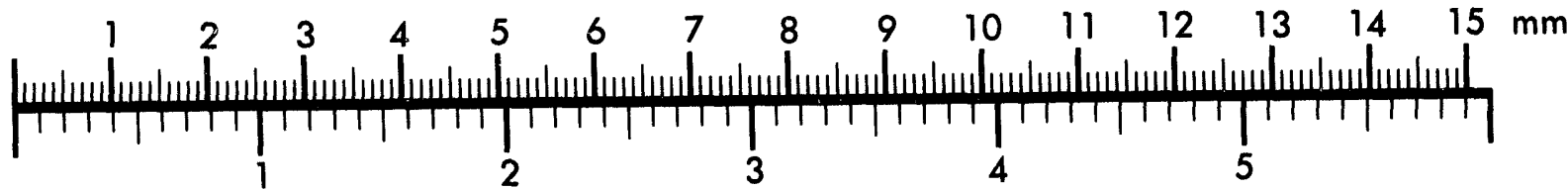
Inches
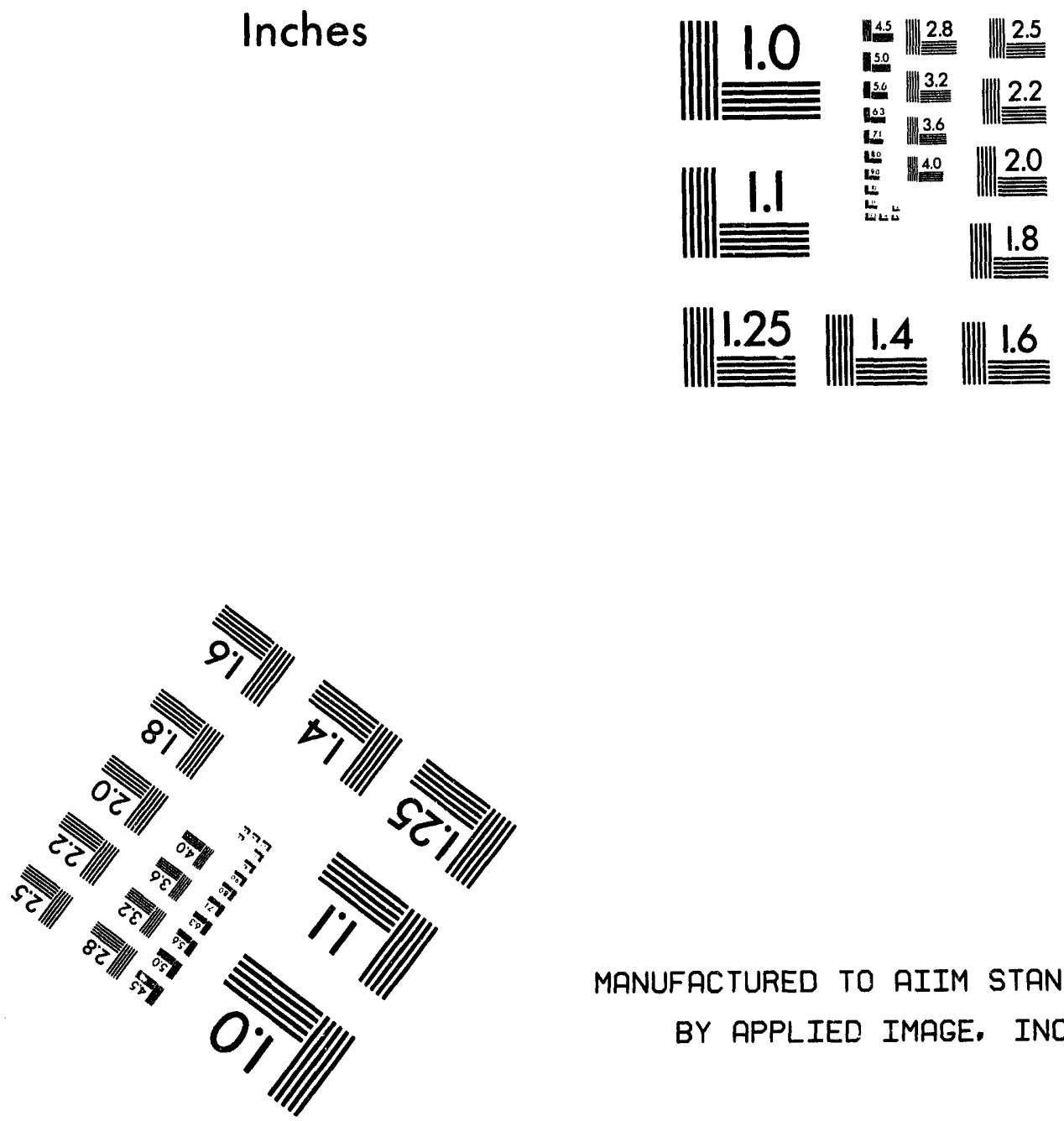

MANUFACTURED TO AIIM STANDARDS

BY APPLIED IMAGE, INC.

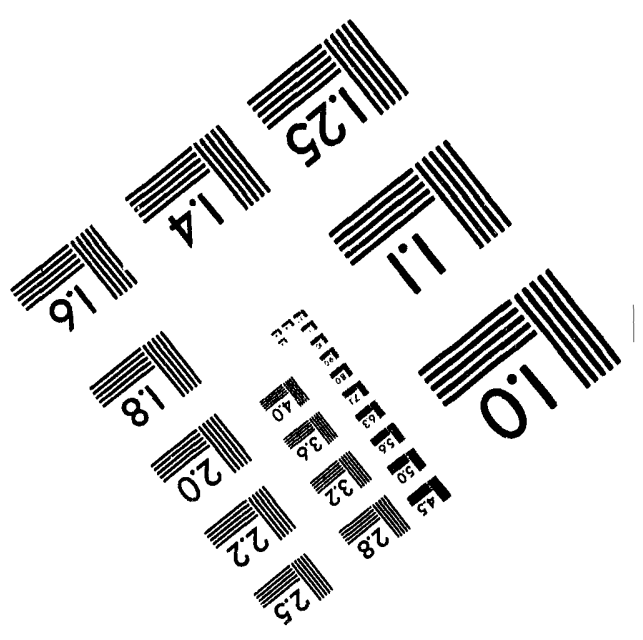



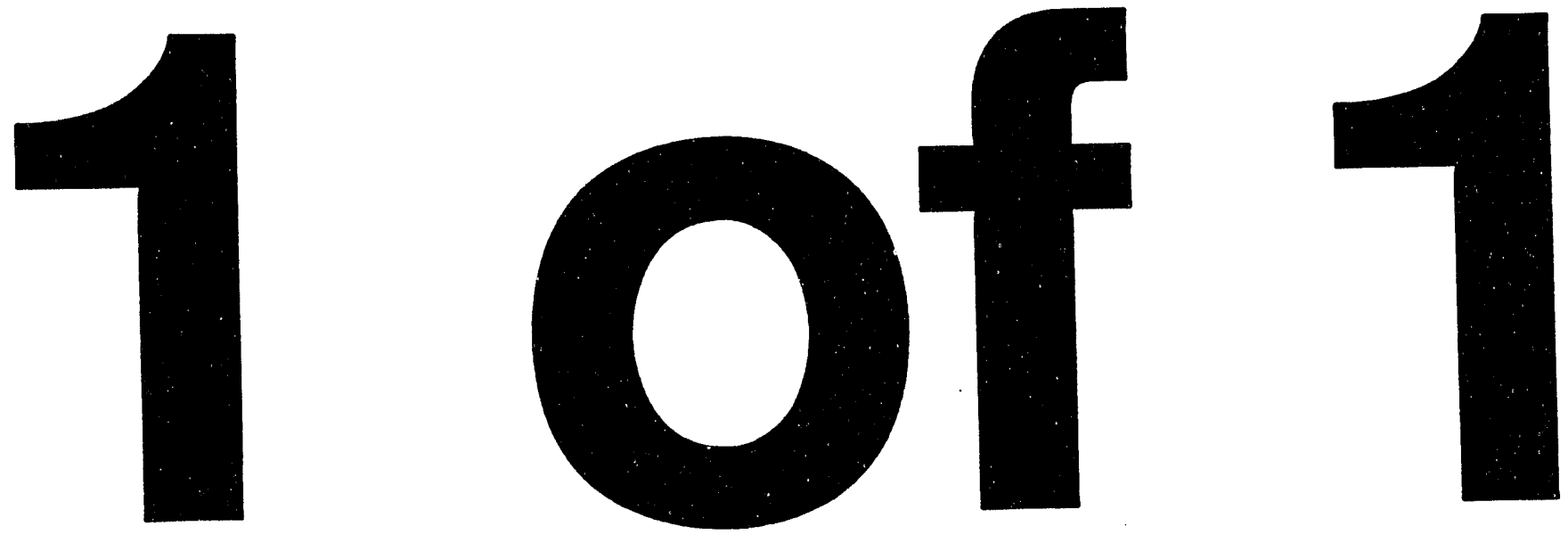
Los Alamos National Laboratory

\section{Characterization and Analysis of NaI(TI) and BGO Detectors}

John Ryan Harrison

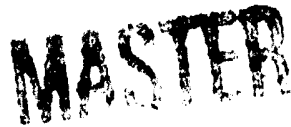

DISTRIBUTION OF THIS DOCUMENT IS UNLIMITED<smiles>C1CCCC1</smiles> 


\section{Introduction}

There have been many studies concerning the performance characteristics of $\mathrm{NaI}(\mathrm{Tl})$ and $\mathrm{BGO}$ scintillating crystals, most of which generate data by algorithms rather than from experimentation. Those studies which do deal with collected data, however, usually test only a few detecting units. It was, therefore, the purpose of this project to develop a characterization method (see Appendix 1) and to characterize a large number of scintillators of various sizes and histories as well as to create a performance profile based on the data collected. The energy ranges at which the detectors show relatively good resolution $\%$ and photo peak efficiency was also desired for future reference. Enough statistical data were collected and analyzed so that a differentiation between those detectors which perform well and those that do not can be made.

\section{Technical Data}

\section{Experimental Setup}

One major consideration in any radiation detection experiment is the amount of background radiation included in the overall data. Collected background data indicated that approximately $10 \%$ of the experimental data was due to the natural decay of elements found in the structure of the building. In several cases this was of large enough influence to overshadow the desired signals. As a result, the testing apparatus was moved to a low background counting facility. Partially subterranean, the room is constructed of one foot thick Pre-World War II battleship steel. Upon further investigation it was determined that the facility cuts unshielded background readings by a factor of 20 over a 500 live minute duration.. The unshielded background readings in the facility are a factor of 2 greater than a standard $3 \times 3 \mathrm{NaI}(\mathrm{Tl})$ Production Counter shielded with six inches of lead. All detectors were tested using the same sources; ${ }^{241}$ Americium, ${ }^{13} \mathrm{i}$ Cesium, and ${ }^{60}$ Cobalt with respective activities of $10.0+/-0.2 \mu \mathrm{Ci}, 10.28+/-0.02 \mu \mathrm{Ci}$, and $3.69+/ .0 .02 \mu \mathrm{Ci}$. In each case, the source was located $25 \mathrm{~cm}$ from the face of the detector along the crystal's primary axis. This was true for all except detectors 42 and 43 , which had to be tested from the side due to their being mechanically placed in coincidence. The facility also offers another major benefit to the purity of the collected data. No lead shielding was necessary and the size of the room allowed the testing apparatus to be placed at least 4 feet from each wall. This greatly reduces the possibility of collecting Compton scattering photon, annihilation radiation, and lead $\mathrm{X}$-rays from nearby shielding. (1)(4)

\section{Electronic Setup}

The following supplies were utilized for these experiments: RG $71 \mathrm{~B} / \mathrm{U}$ Coaxial cable, a Bertan model 323 High Voltage Power Supply, an Ortec model 113 Pre-Amp, an Ortec model 114 PreAmp Power Supply, a Tennelec model TC244 Amplifier, a Canberra MCA 8100, and an oscilloscope for gain and focus adjustments on the detector base. The pre-amp capacitance remained fixed at $200 \mathrm{pF}$ for all $3 \times 3,5 \times 5,6 \times 6$, and $8 \times 8$ detectors. For the $1 \times 1,2 \times 2$, and BGO units the pre-amp was set to $0 \mathrm{pF}$. For those detectors not possessing an integral base an Ortec model 266 base was used. Those requiring a different size base used homemade units. A diagram of the setup and a list of cable lengths is provided. 


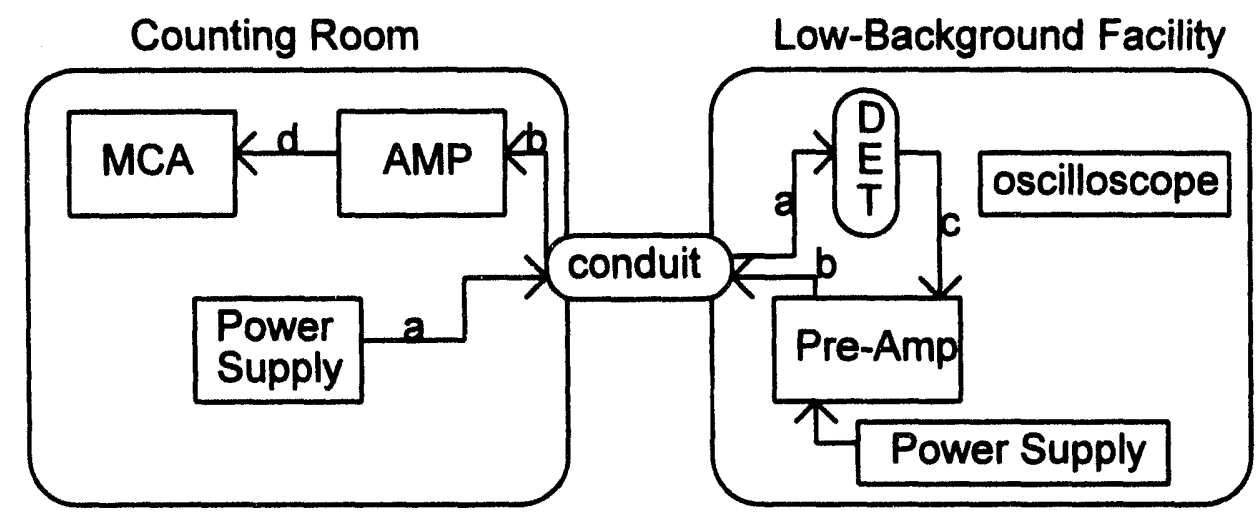

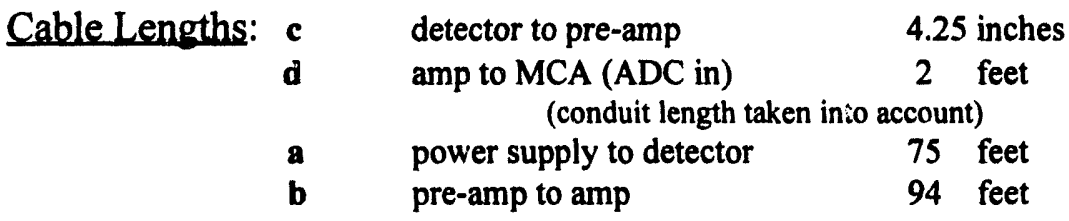

\section{Unit History}

Several detectors had never been used and, therefore, had no operating history. The others range from a couple to nearly thirty years old. Many have dented canisters, possibly resulting in damaged crystals or internal electronics. These things would of course affect the performance of the detector and have therefore been summarized. (see Appendix 3.1)

\section{- NaI(TI) vs. BGO Detectors}

Several differences between $\mathrm{NaI}(\mathrm{Tl})$ and $\mathrm{BGO}$ detectors are of relevance in this project. For a more complete comparison of their properties see Radiation Detection and Measurement by Glenn Knoll (5), specifically page 231 , table 8-3. BGO crystals have a little over twice the density of $\mathrm{Nal}(\mathrm{Tl})$, meaning that they have a higher $\mathrm{Z}$ number. As a result, BGO crystals capture more incident gamma rays. However, statistically, fewer photons make it to the photo cathode of the PMT and they therefore have worse resolution than a $\mathrm{NaI}(\mathrm{Tl})$. The fewer photons also requires that a higher gain be used on a BGO. Also, the decay constant of a BGO is longer than that of $\mathrm{Nal}(\mathrm{Tl})$, requiring minor alterations on the amplifier. 


\section{Data Analysis}

The data that have been collected has been archived by the CST Counting Room for future reference. All data, except background, were of a 10 live-minute duration. From this data the detector characteristics have been determined and profile spreadsheets created (see Appendices $3.2 \& 3.3$ ). These profiles include each detector's resolution for each of the three sources. This is of primary concern in that, along with the photo peak efficiency, it allows one to discriminate between source peaks so as to better determine unknown sources and to detect several peaks of comparable energies. The peak to total ratio is extremely relevant in that, when used with Monte Carlo data, the intrinsic efficiency of the detector can be determined. When used in conjunction with the photo peak efficiency as well, it allows the overall absolute efficiency to be calculated. The photo peak efficiency, in itself, is necessary and useful in that contributions from Compton scattered photons have little effect on it.(2) Since this is the case, the photo peak efficiency is a more accurate measure of the emission rate of the source. It is preferable to use the photo peak efficiency because it is not greatly influenced by variable conditions. ${ }^{(2)(6)}$ The Cs ratio is included merely for the comparison of detector performance. Also, the CPS (counts per second) and peak areas are shown as the raw data from which the above characteristics were derived. Explanation of all formulae used appears in Appendix 2.

It was of interest to compensate for the data lost by low level discrimination (LLD) as well as to remove the effects of $\mathrm{X}$-rays from the data. As a result, the reduced data profile was generated. In the case of LLD compensation the first data collected was extended horizontally to the ordinate axis and the new region was added to the data. This was done in the cases of Cesium and Cobalt. $\mathrm{X}$-ray subtraction was performed on both Cesium and Americium. This was the only form of data reduction used on Americium since the X-ray subtraction is roughly equivalent to the LLD cutoff. In the case of Cobalt, the 1173 and $1332 \mathrm{KeV}$ peaks were added to determine a new peak area, peak to total ratio, CPS, and photo peak efficiency.

\section{Graphs}

The following graphs are taken directly from the profiles that appear in Appendices 3.2 \& 3.3. A reference number was used in the cases where the profile order was inappropriate; a reference number to detector number correspondence table has been included for convenience. 


\section{GRAPH}

\section{REFERENCE NUMBERS}

\section{Graph}

Reference

Number

\section{Detector}

Number

$\begin{array}{cc}1 & 41 \\ 2 & 31 \\ 3 & 32 \\ 4 & 33 \\ 5 & 34 \\ 6 & 36 \\ 7 & 37 \\ 8 & 38 \\ 9 & 39 \\ 10 & 40 \\ 11 & 1 \\ 12 & 2 \\ 13 & 3 \\ 14 & 4 \\ 15 & 5 \\ 16 & 6 \\ 17 & 7 \\ 18 & 8 \\ 19 & 9 \\ 20 & 10 \\ 21 & 11 \\ 22 & 12 \\ 23 & 13 \\ 24 & 14 \\ 25 & 15 \\ 26 & 16 \\ 27 & 17 \\ 28 & 18 \\ 29 & 19 \\ 30 & 20 \\ 31 & 21 \\ 32 & 22 \\ 33 & 29 \\ 34 & 24 \\ 35 & 25 \\ 36 & 26 \\ 37 & 27 \\ 38 & 28 \\ 39 & 42 \\ 40 & 43 \\ 41 & 44 \\ & \end{array}$

NOTE : Due to Non-Responsive behavior, detectors 23,30 , and 35 have intentionally been removed from the graphs. 


\section{Nal(TI) Relative Resolutions}

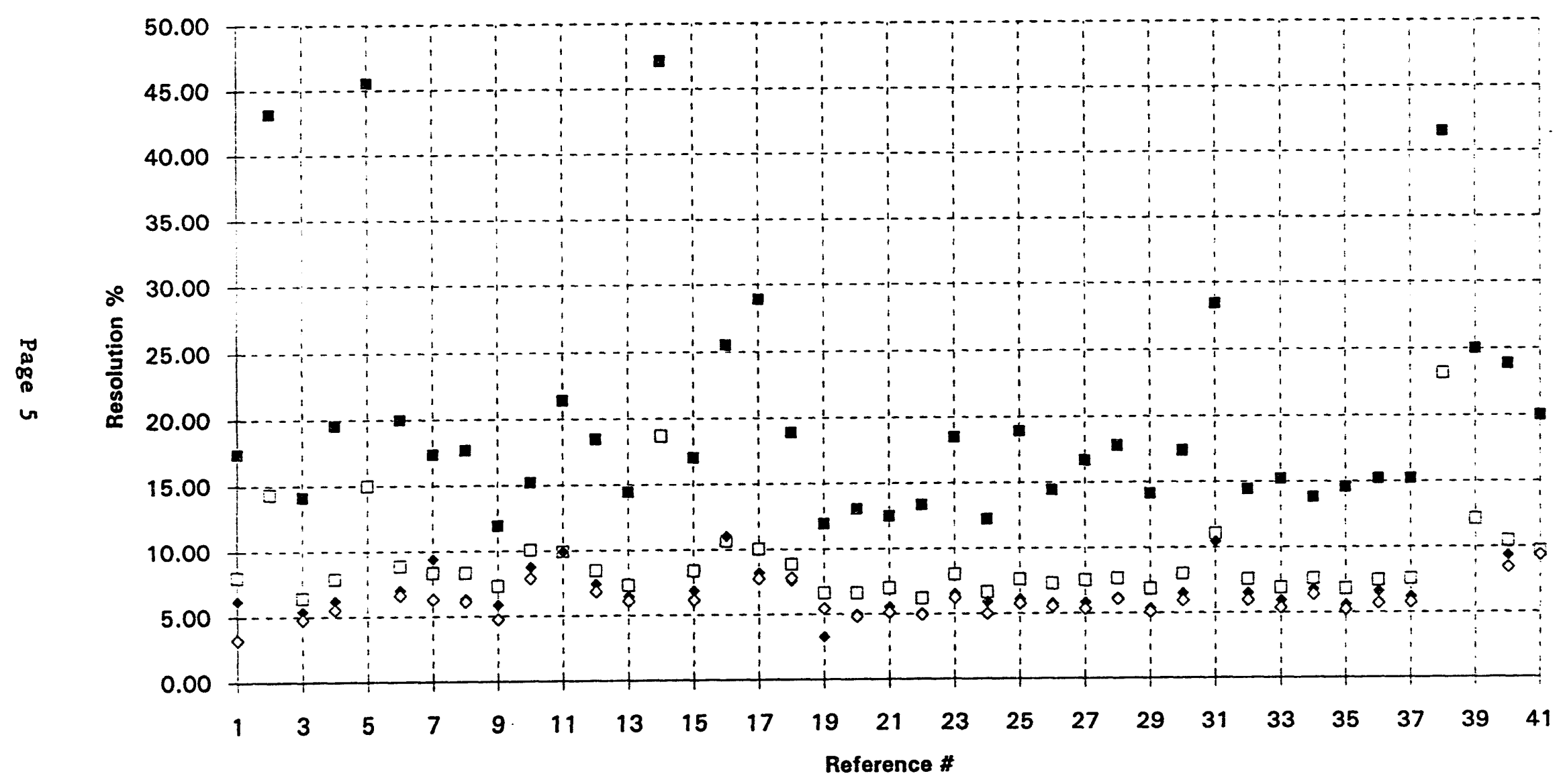

DamRes X DCSRES X • CORES X OCORES X 


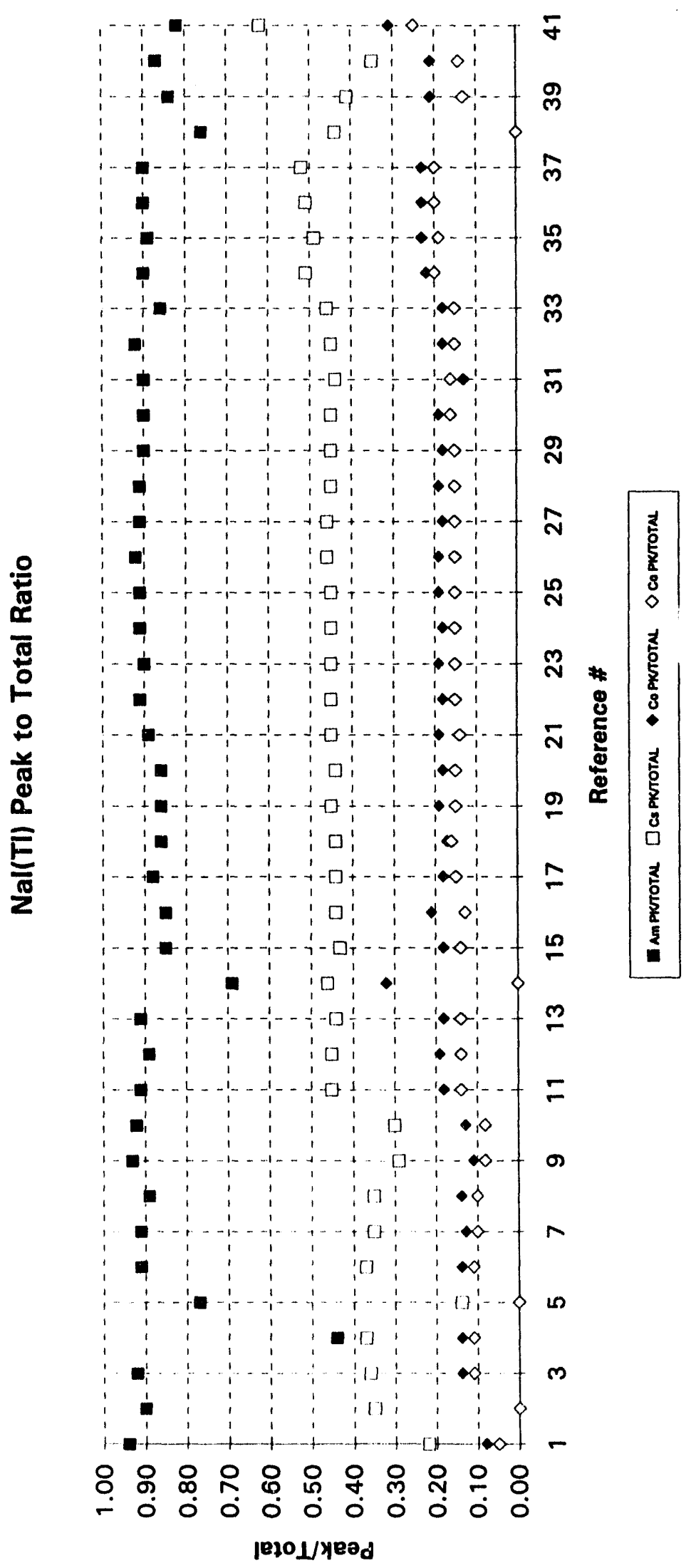

Page 6 


\section{Nalfîl) Efficiencies}

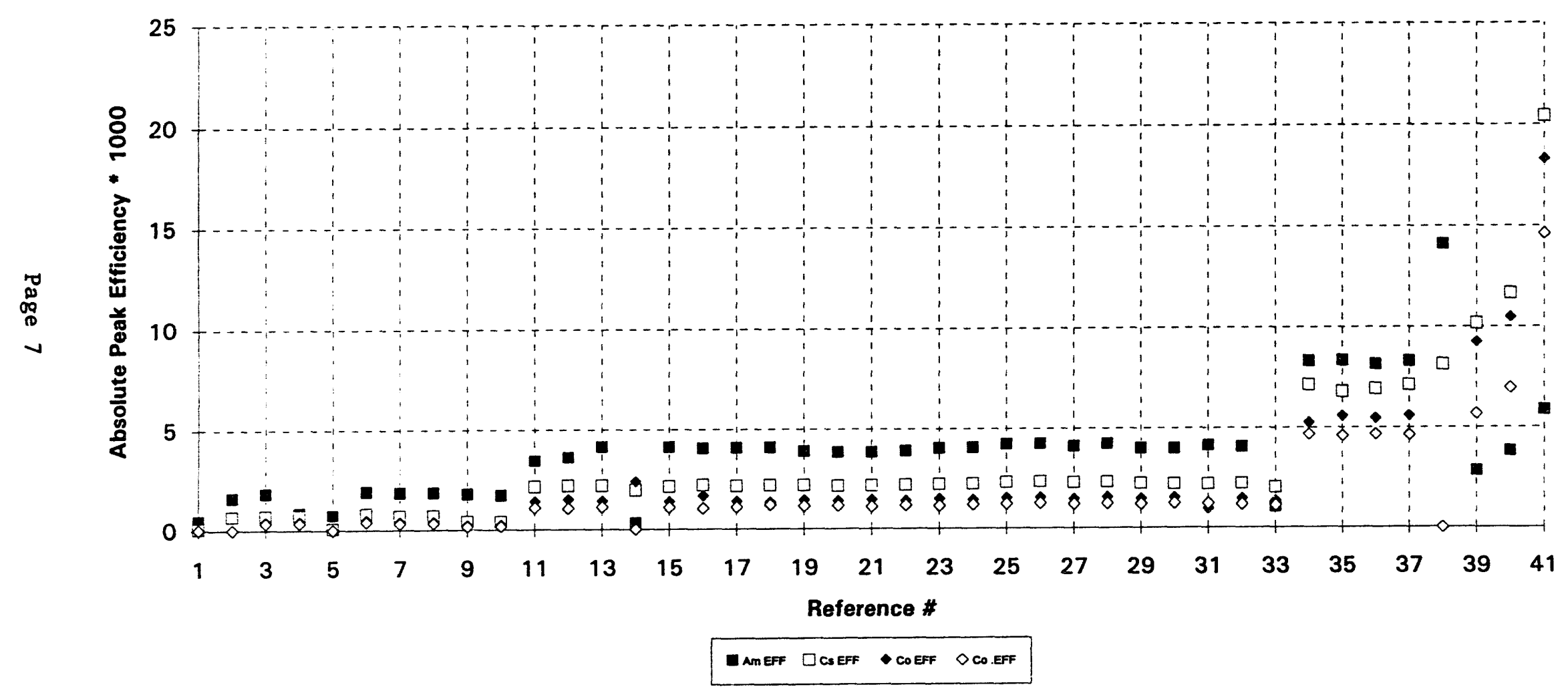


Nal(TI) Resolution vs. Log Energy

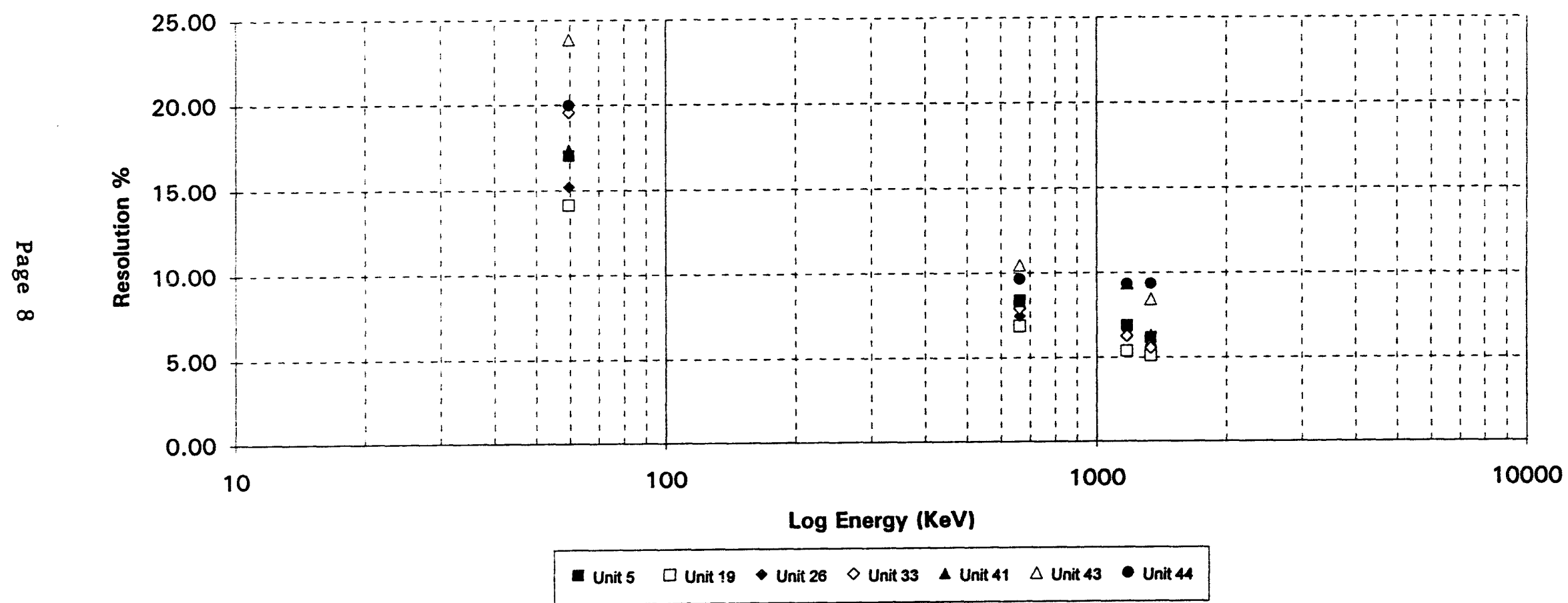




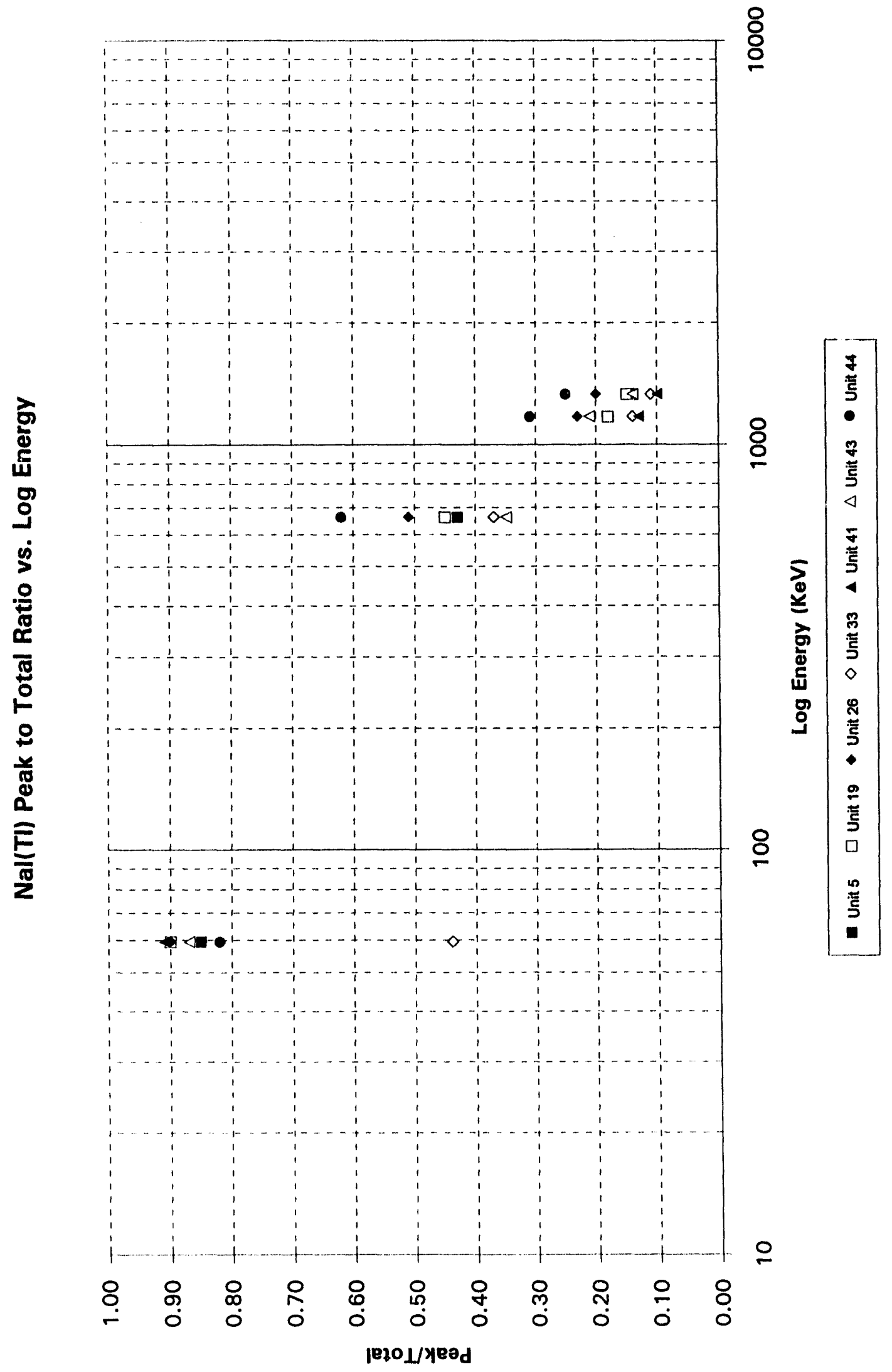

Page 9 


\section{(Post Data Reduction) Peak to Total Ratio}

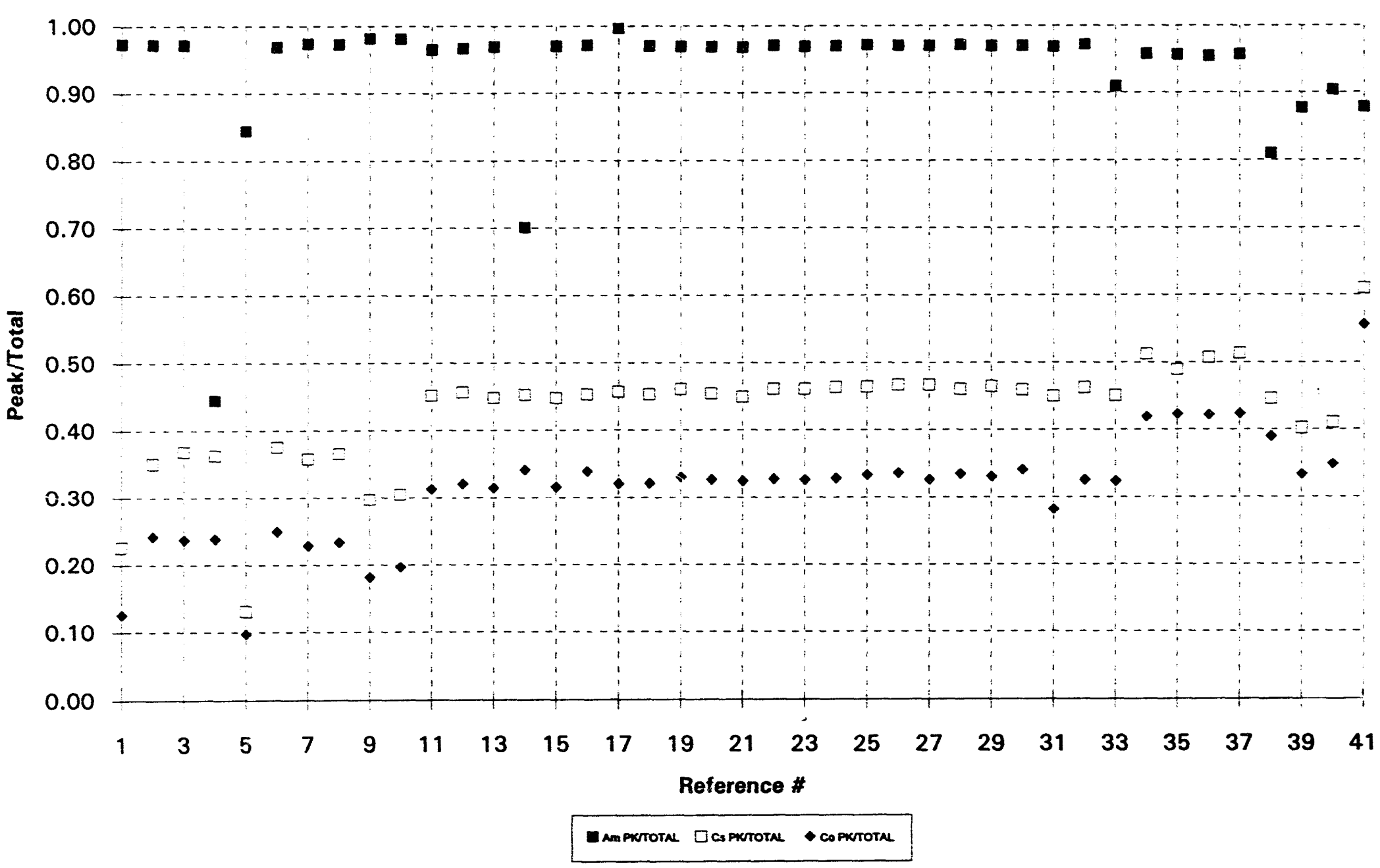




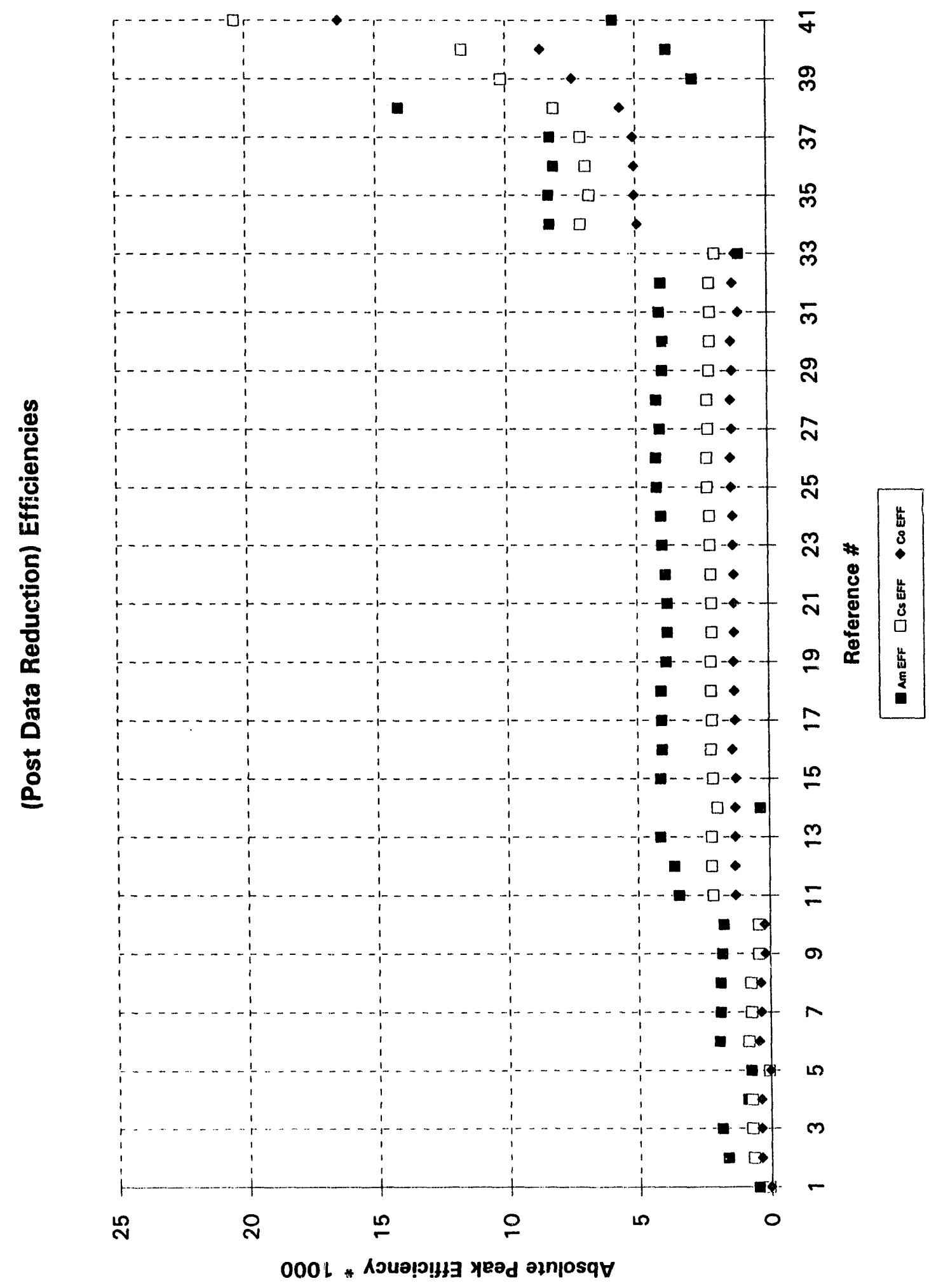




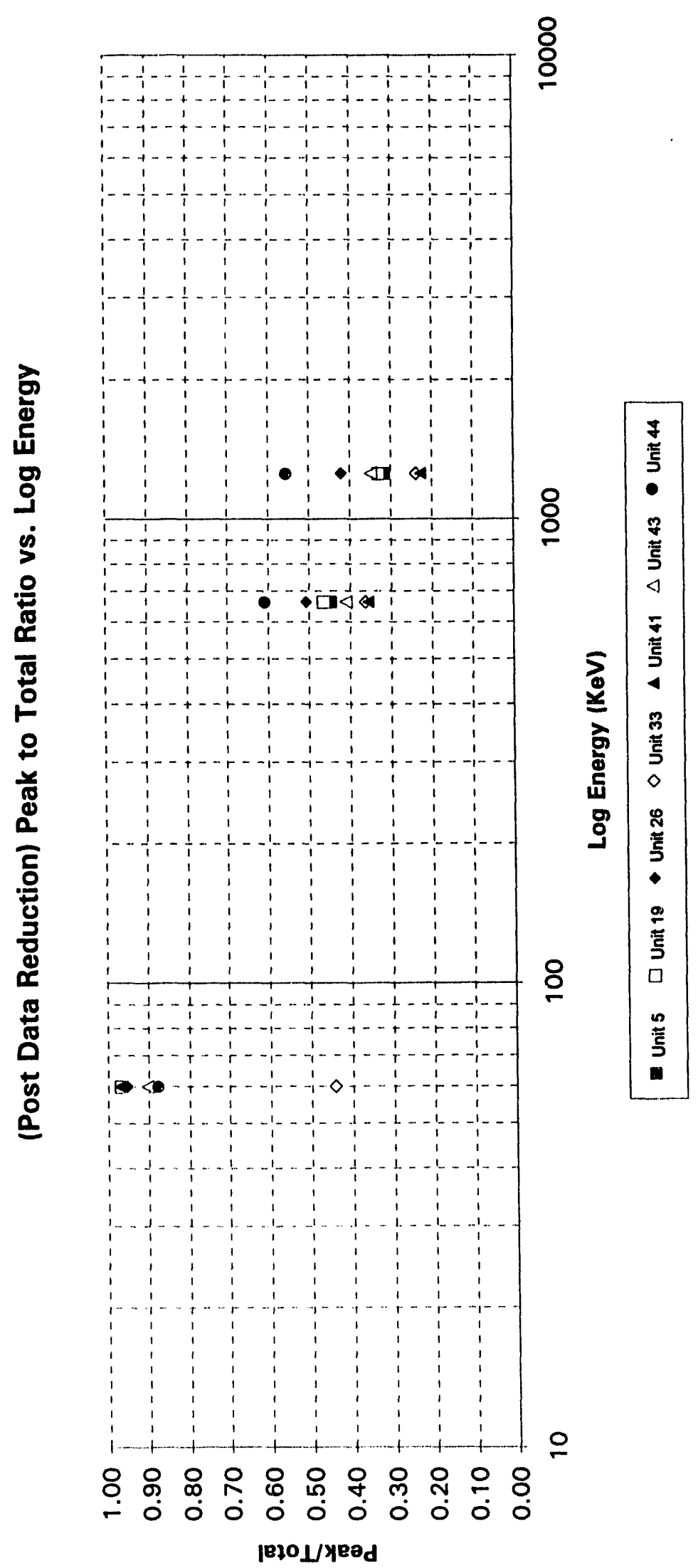

Page 12 


\section{BGO Relative Resolutions}

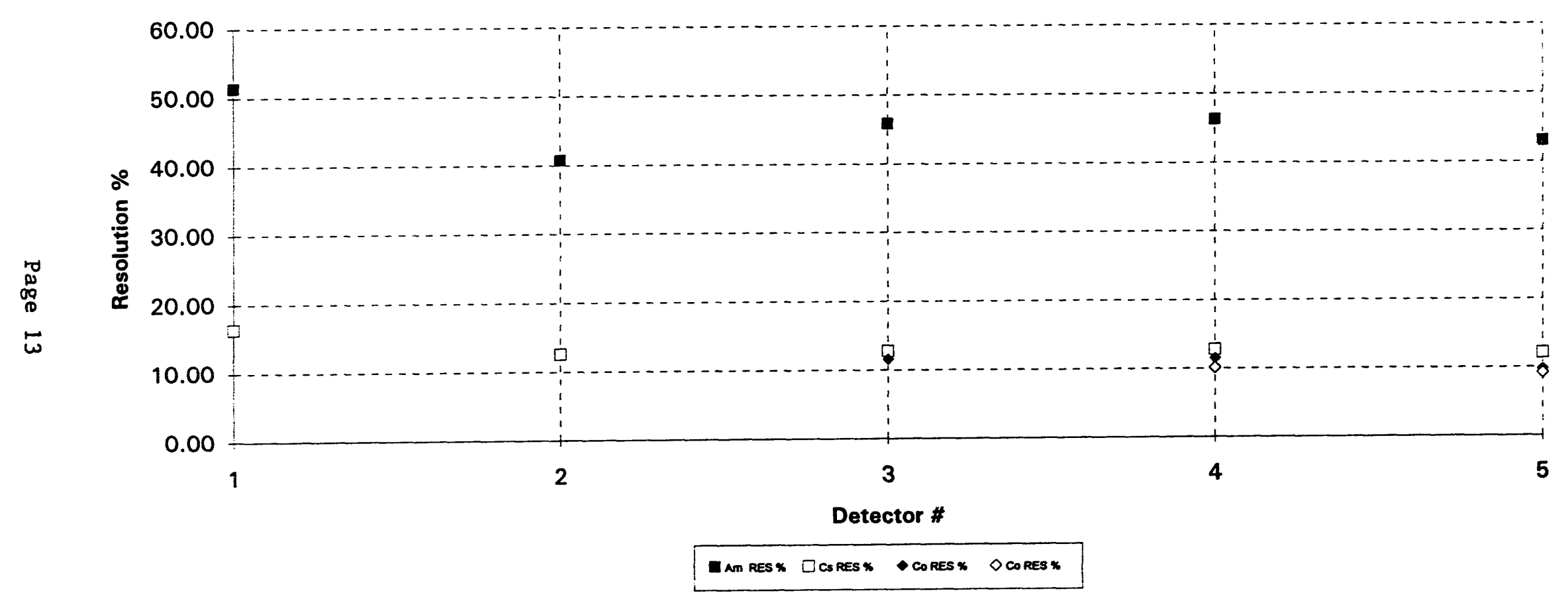




\section{BGO Peak to Total Ratio}

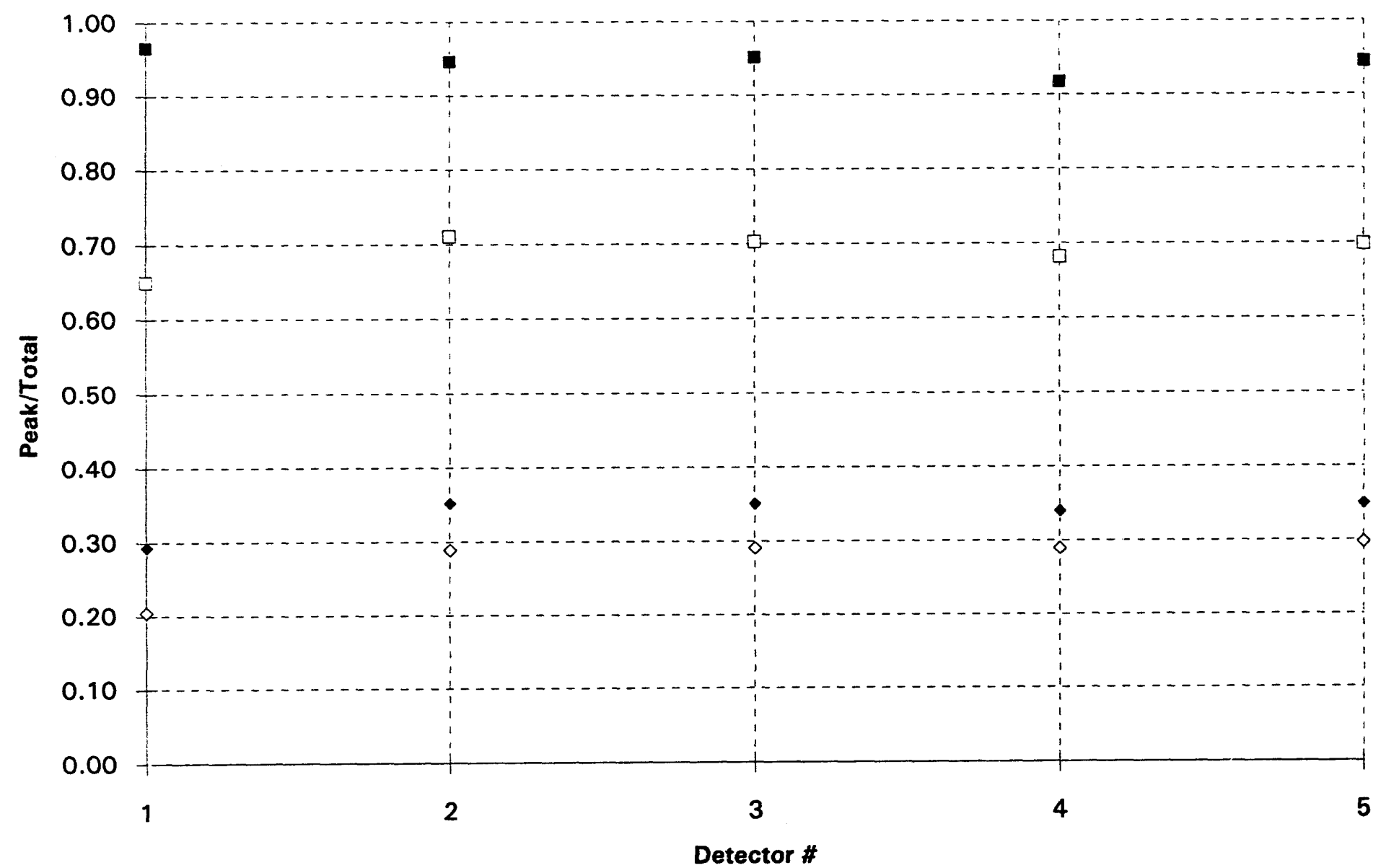

- ampirtotal ocspictotal •copktotal scopktotal 
SI $28 e_{d}$

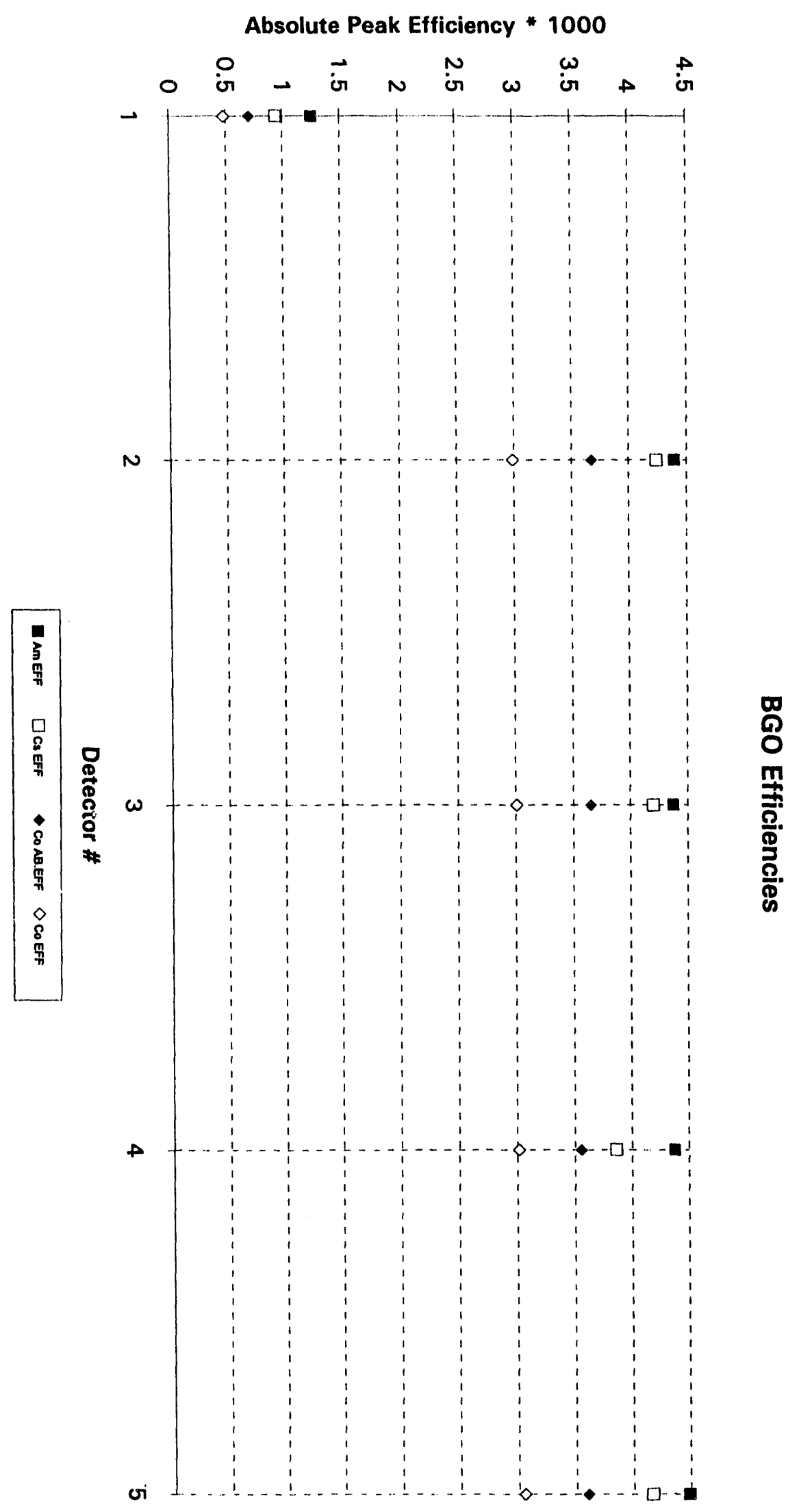


BGO Resolution vs. Log Energy

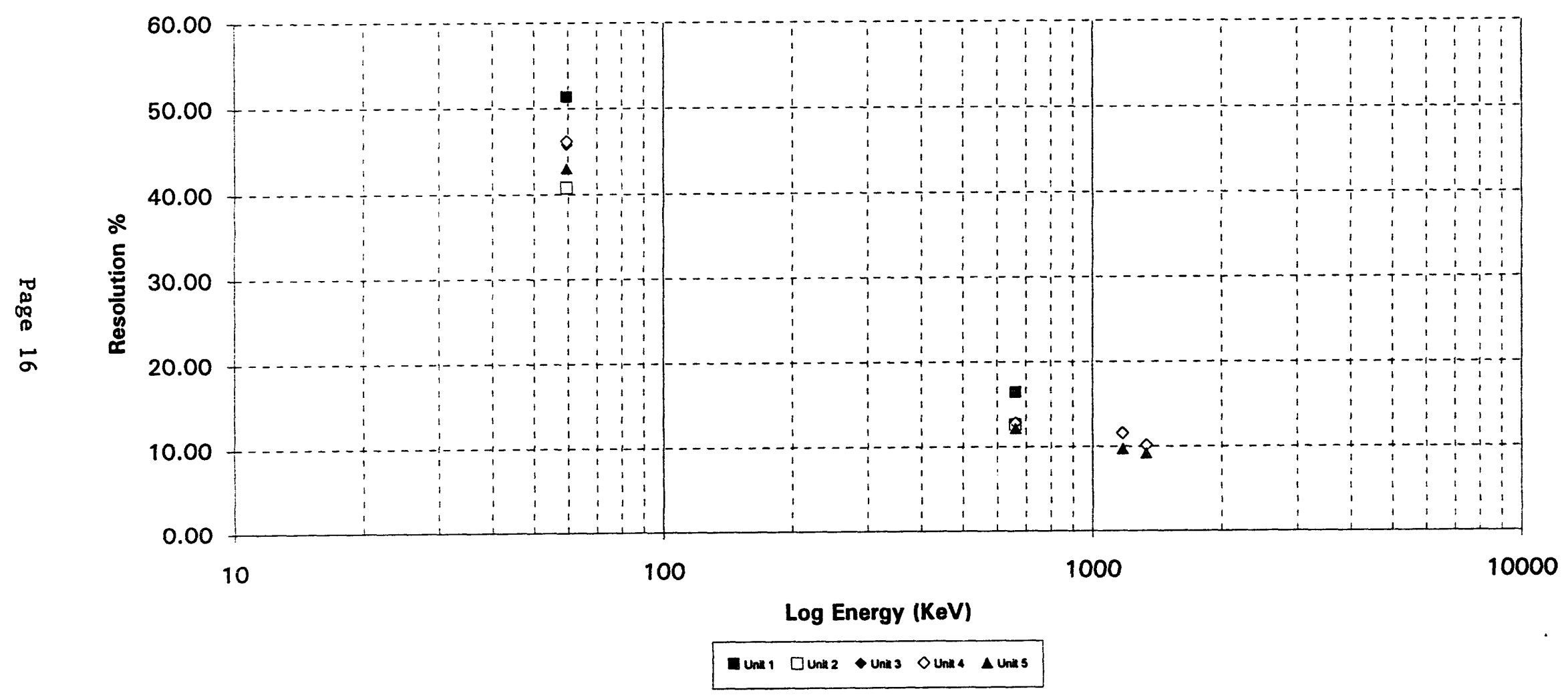


BGO Peak to Total Ratio vs. Log Energy

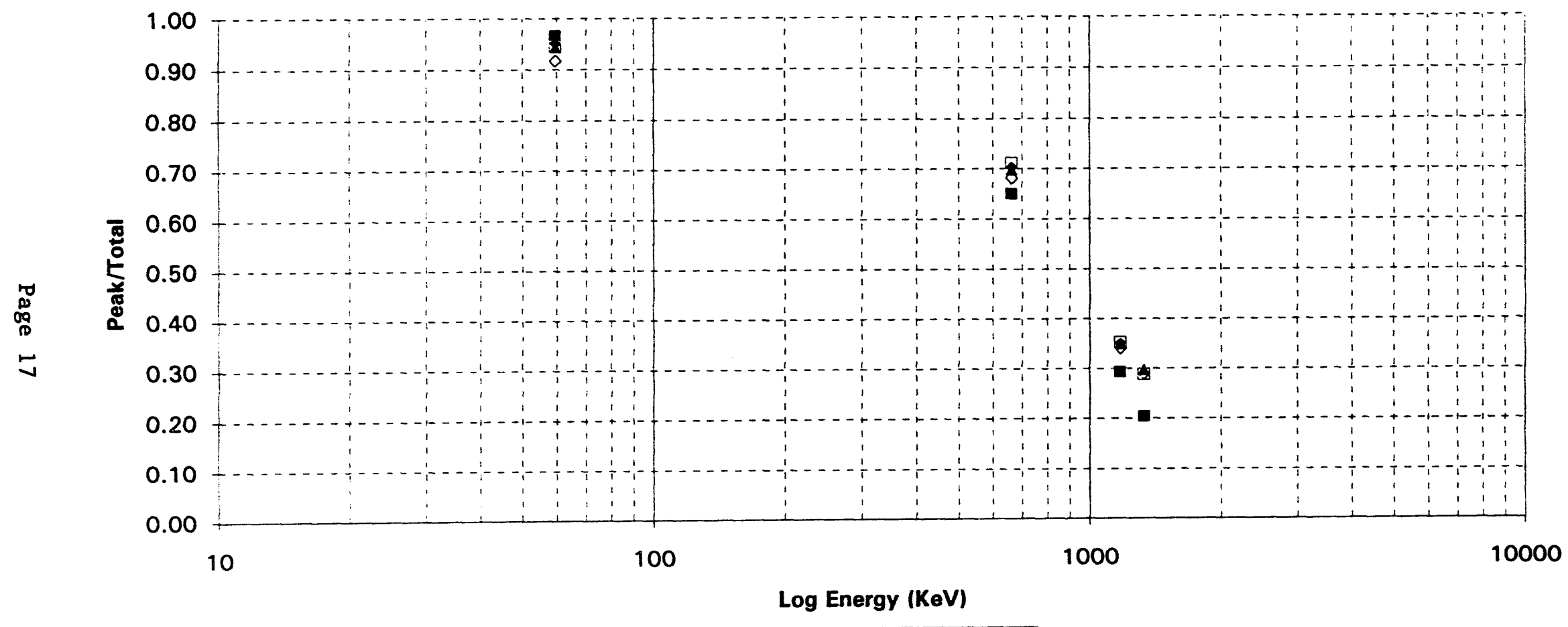

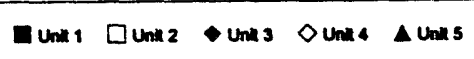




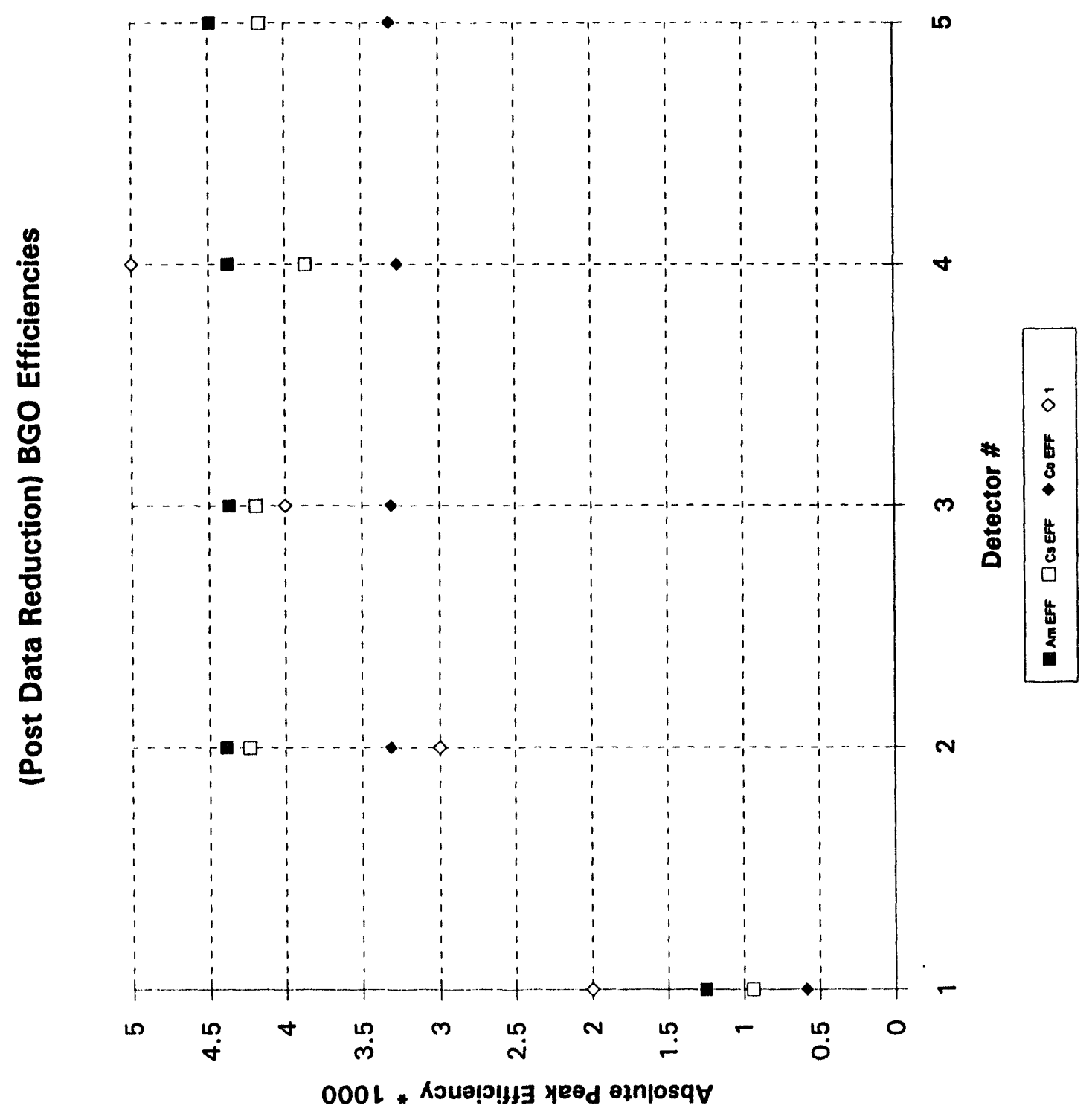


(Post Data Reduction) BGO Peak to Total Ratio

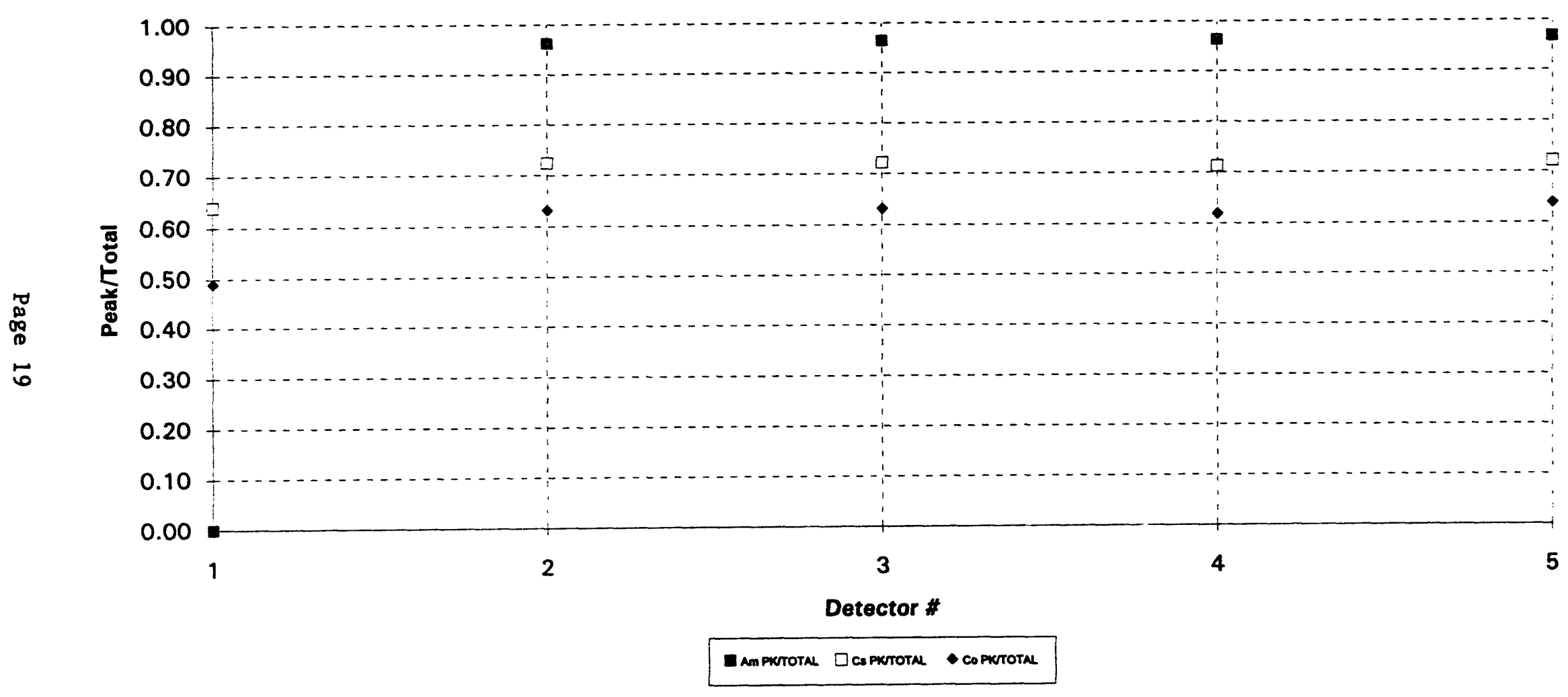




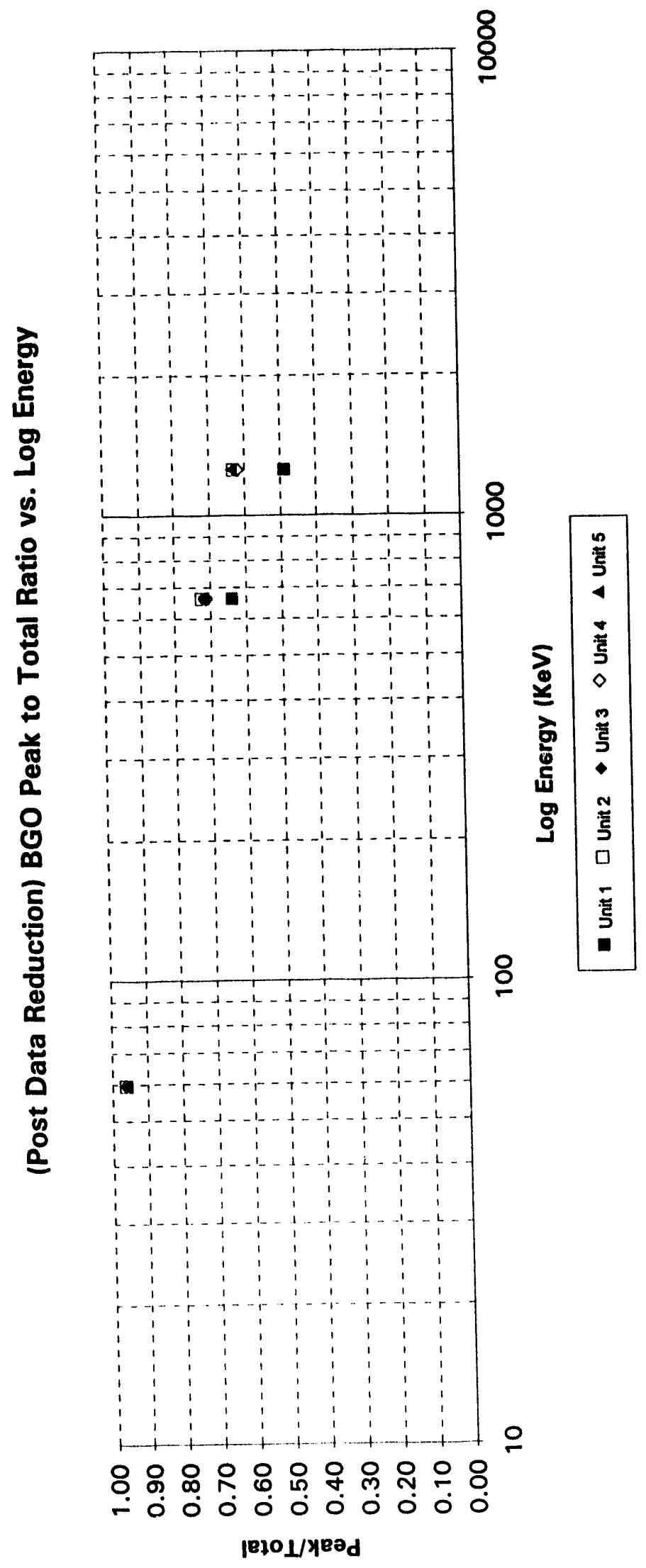

Page 20 


\section{Discussion}

Several trends appear obvious from the graphed data. It is of great interest that the peak to total ratio is remarkably uniform, though the resolution varies greatly between detectors. The photo peak efficiency is also noticeably consistent, which simply means that the manufacturer machines the crystals to consistent dimensions. Another point of interest is the fact that age does not seem to be a factor in the performance of the detector. From the profiles generated it has been determined that a typically good detector has the following properties:

$\mathrm{NaI}(\mathrm{Tl})$

$\begin{array}{lcccc}\text { Size (2x2) } & \text { Energy (59.5 KeV) } & \text { (662 KeV) } & \text { (1173 KeV) } & (1332 \mathrm{KeV}) \\ \text { Resolution \% } & 17 & 8 & 7 & 6 \\ \text { Peak/Total } & 0.9 & 0.45 & 0.19 & 0.15 \\ \text { Efficiency * } 1000 & 1.8 & 0.7 & 0.4 & 0.3\end{array}$

Size $(3 \times 3)$

Resolution \%

Peak/Total

Efficiency * 1000

16

0.9

4.0

Size $(5 \times 5)$

Resolution \%

Peak/Total

Efficiency * 1000

15

0.9

8.3

BGO

Size $(3 \times 3)$

Energy (59.5 KeV)

Resolution \%

Peak/Total

45

Efficiency * 1000
0.95

4.4
7

0.45

2.1

7

0.45

7.0
6.5

0.19

1.4

0.15

1.2

6

0.19

5.5

0.15

4.6

It is very important to note that resolution \%, peak to total ratio, and photo peak efficiency $\left({ }^{*} 1000\right)$ all seem to decline with increasing energies. This is due to the fact that at higher energies the gamma rays are statistically more likely to escape capture within the crystal. Several anomalies appear in the data and for which an explanation cannot be offered at this time. The most notable anomalies are those dealing with resolution \%. Several detectors display extremely bad resolutions. These tend to be in the lower end of the energy scale. Many of the detectors show bad resolution \% in the $59.5 \mathrm{KeV}$ Americium peak. However, a few appear to have resolutions, specifically in the $1173 \mathrm{KeV}$ Cobalt peak, that are extremely good. These anomalies are much lower than their fellow detectors with a resolution \% between 3 and 5 . One possible solution for this activity is given by both Heath and Knoll.(3)(7) Ionization within the detecting crystal, and other sources discussed by Knoll, results in statistical fiuctuations which invariably effects the resolution of the unit. It also interesting to note that the slope of the Resolution \% vs. Log Energy graph, included with this report, is consistent with Heath's determination. (3) The graph included in this report, however, is lower on the resolution \% scale, implying that the detectors tested were of a better resolution $\%$. 


\section{Acknowledgments}

I would like to acknowledge the contributions of Malcolm Fowler, whose expertise and guidance were integral to this project.

\section{References}

1. R.L. Heath, Scintillation Spectrometry Gamma Ray Spectrum Catalogue, 2nd Ed. Vol. 1, pp. 10-18, U.S. Atomic Energy Commission, 1968.

2. ibid. p. 22

3. ibid. p. 9 , specifically figure 6 .

4. Glenn F. Knoll, Radiation Detection and Measurement, 2nd Ed. p. 231, John Wiley and Sons, NY 1989.

5. ibid. pp. 230-232, 234-236.

6. ibid. pp. 117,119 .

7. ibid. pp. 115-116. 


\title{
Appendix 1
}

\section{r...(TI) and BGO Scintillation Detector Characterization}

\author{
July, 1994 \\ rev 3.0
}

\section{1.) Setup :}

Set MCA to 1024 channels.

Calibrate spectrum with Cesium 137 source.

Start with positive HV of $1 \mathrm{kV}$.

Use amplifier shaping time of 1.5 microsec.

Adjust amplifier gain to put Cesium peak near the center of the display ( channel 450 ).

Once this is done, amplifier gain should remain fixed for a given detector.

\section{2.) For Each Tube :}

Check the amplifier pole zero and adjust.

In the Steel Room, maximize the pulse amplitude with PMT focus using O-scope.

Adjust amplifier gain ( slightly) and HV to place cesium peak in channel 450.

\section{3.) Counting :}

Place source at $25 \mathrm{~cm}$ from detector face --- 3 runs per tube.

Record jug -- mass -- start time.

Record long enough to a well defined peak --- around 10 minutes.

Begin data acquisition sequence.

At end of run output spectra to VAX.

Collect hardcopies and file.

\section{4.) Report :}

For each report - detector size, type, $\mathrm{mfg}$, serial number, VAX data output, and notable comments. Report HV, resolution, net peak counting rate = (net peak area/count time), photopeak efficiency, Cs ratio, peak to total ration, etc.

Fill in Excel spreadsheet.

\section{5.) Data :}

$\begin{array}{crc}\text { Nuclide } & \begin{array}{r}\text { Energy } \\ 59.5 \mathrm{keV}\end{array} & \begin{array}{c}\text { Channel } \\ \text { Am (241) }\end{array} \\ & & 40.1 \\ \text { Cs (137) } & 32.0 \mathrm{keV} & 21.8 \\ & 662.0 \mathrm{keV} & 450.0 \\ & & \\ \text { Co }(60) & 1173.0 \mathrm{keV} & 797.0 \\ & 1332.0 \mathrm{keV} & 905.0\end{array}$




\section{Appendix 2}

\section{NaI(TI) and BGO Profile Formulae}

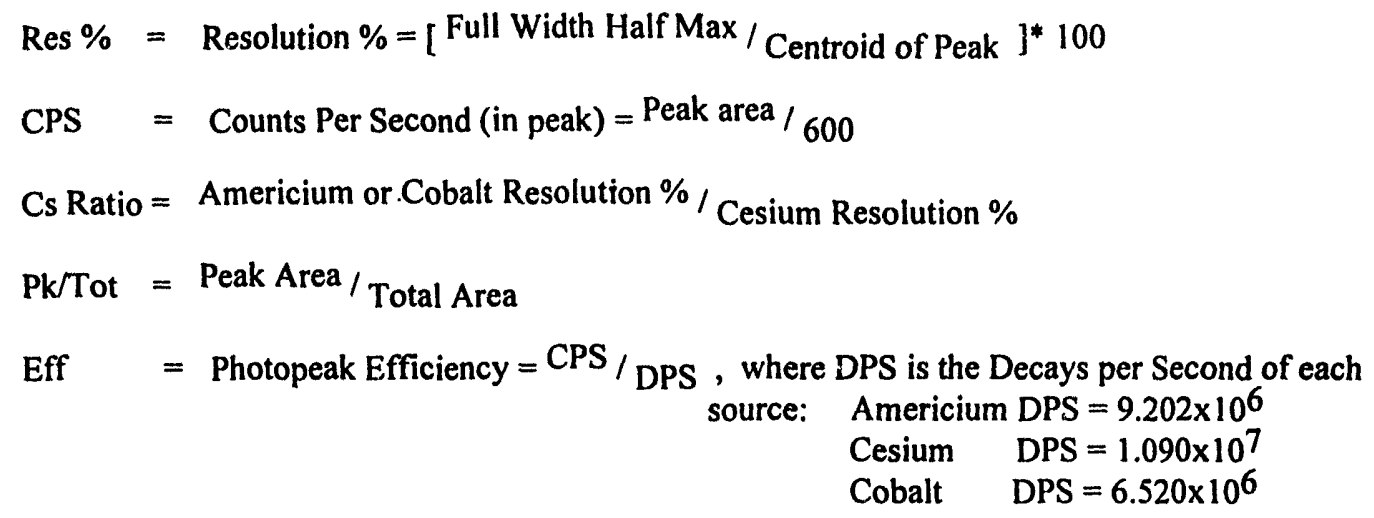

Reduced Data Profile Formulae (only altered formulae shown)

$\begin{array}{lll}\text { Americium } & \mathrm{Pk} / \mathrm{Tot}=\text { Peak Area } / \text { New Total Area } & \begin{array}{l}\text { (using only LLD } \\ \text { compensation) }\end{array} \\ \text { Cesium } & \mathrm{Pk} / \mathrm{Tot}=\text { Peak Area } / \text { New Total Area } & \begin{array}{l}\text { (using LLD } \\ \text { compensation and X-ray } \\ \text { subtraction) }\end{array} \\ \text { Cobalt } \quad \mathrm{Pk} \text { Area }=(1173 \mathrm{KeV} \text { peak area }+1332 \mathrm{KeV} \text { peak area) }\end{array}$

The method used for X-ray subtraction is as follows:

$$
\begin{aligned}
& \text { New Total = Old Total }-\mathrm{X} \text {-ray net } \\
& \qquad \begin{aligned}
\text { X-ray net }=\left(\Sigma X_{i}-\Sigma X_{i}\right)-[ & \left.\left(X_{a}+X_{b}\right) / 2 *(b-a)\right]
\end{aligned} \\
& \text { where : } \begin{aligned}
b & =\text { channel endpoint of right side of } X \text {-ray peak } \\
a & =\text { channel endpoint of left side of } X \text {-ray peak } \\
X_{i} & =\text { Total counts } \\
X_{n} & =\text { Counts at channel } n \text {, where } n \text { is an integer }
\end{aligned}
\end{aligned}
$$




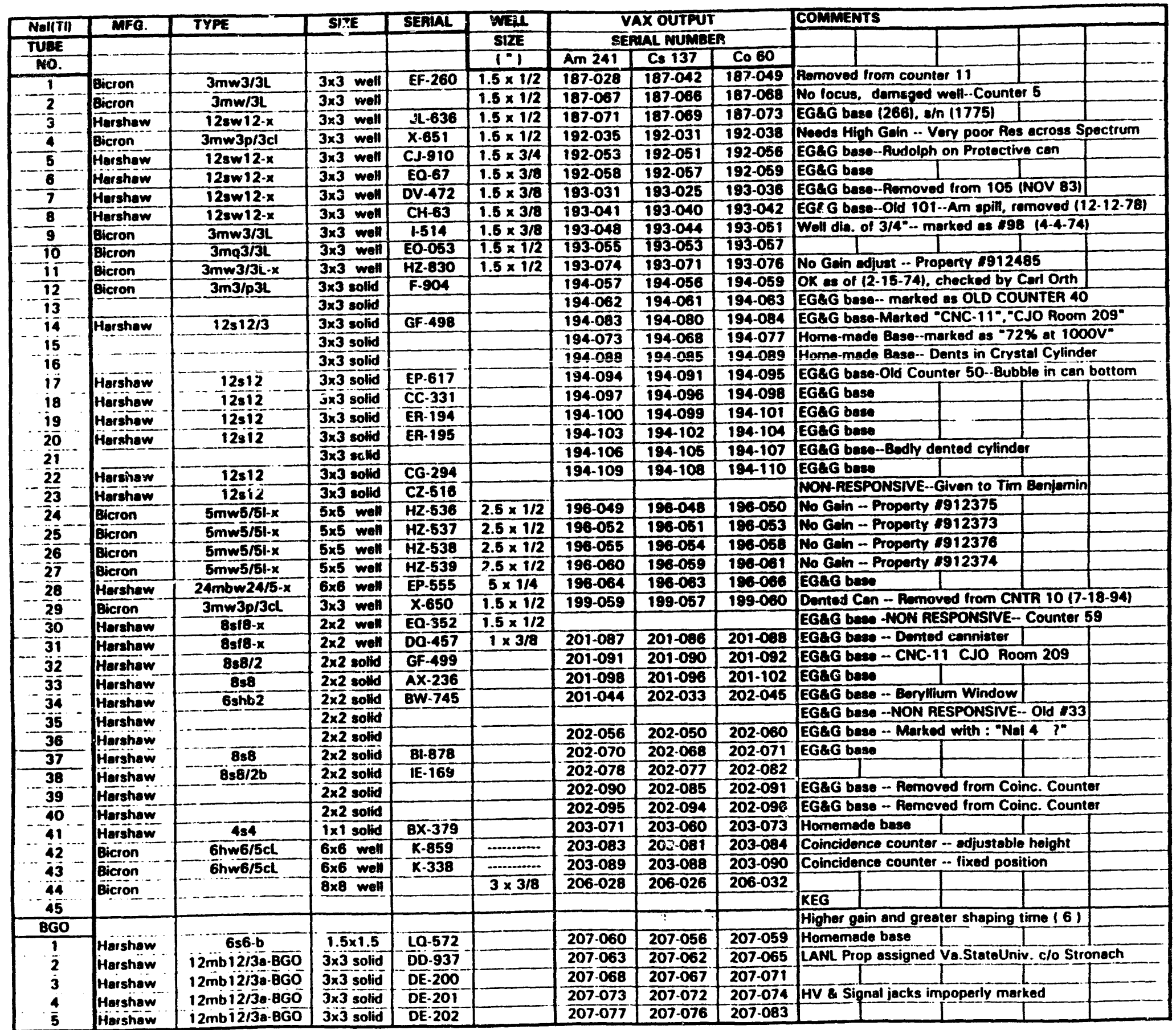




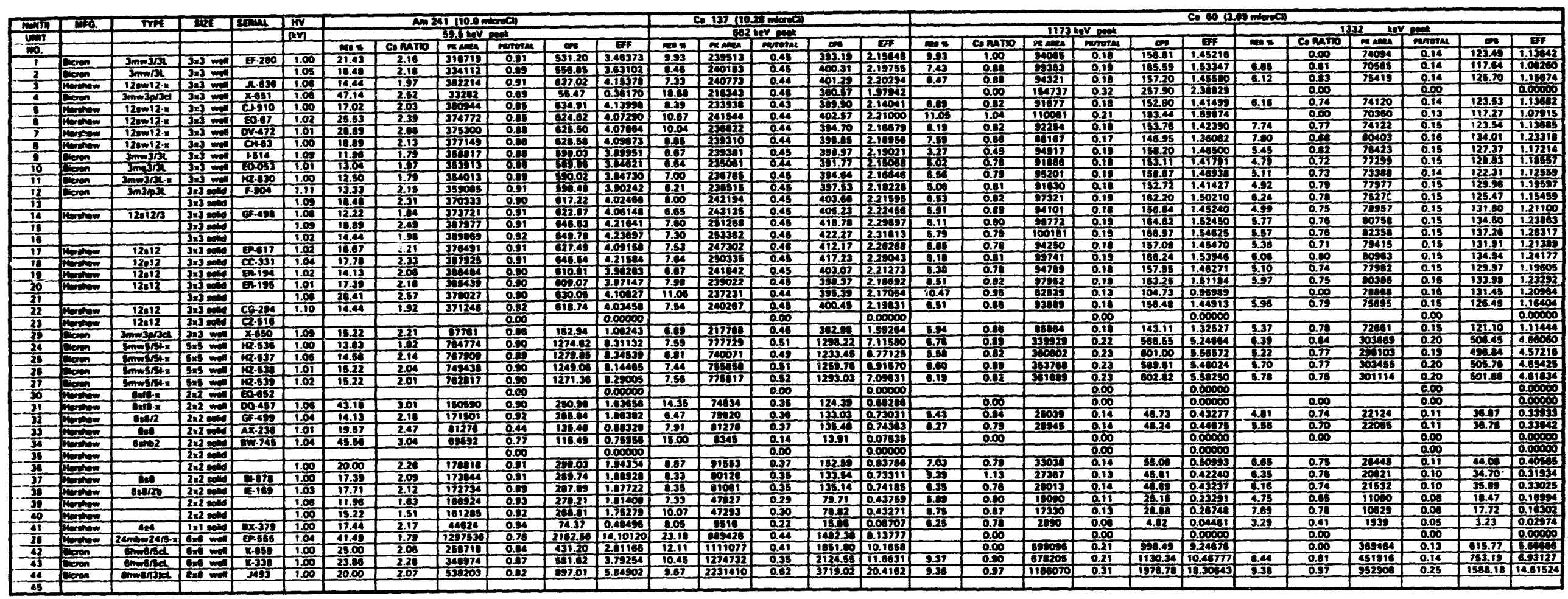




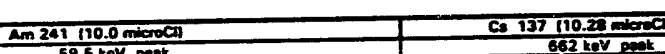

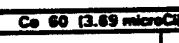

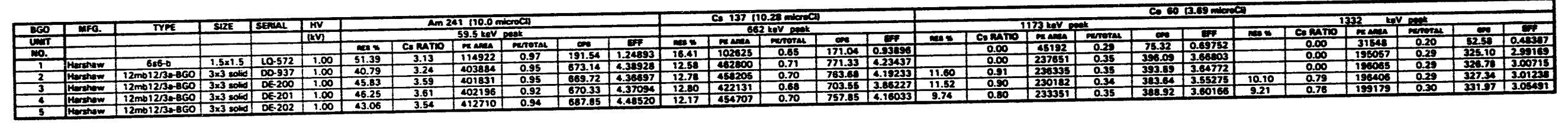




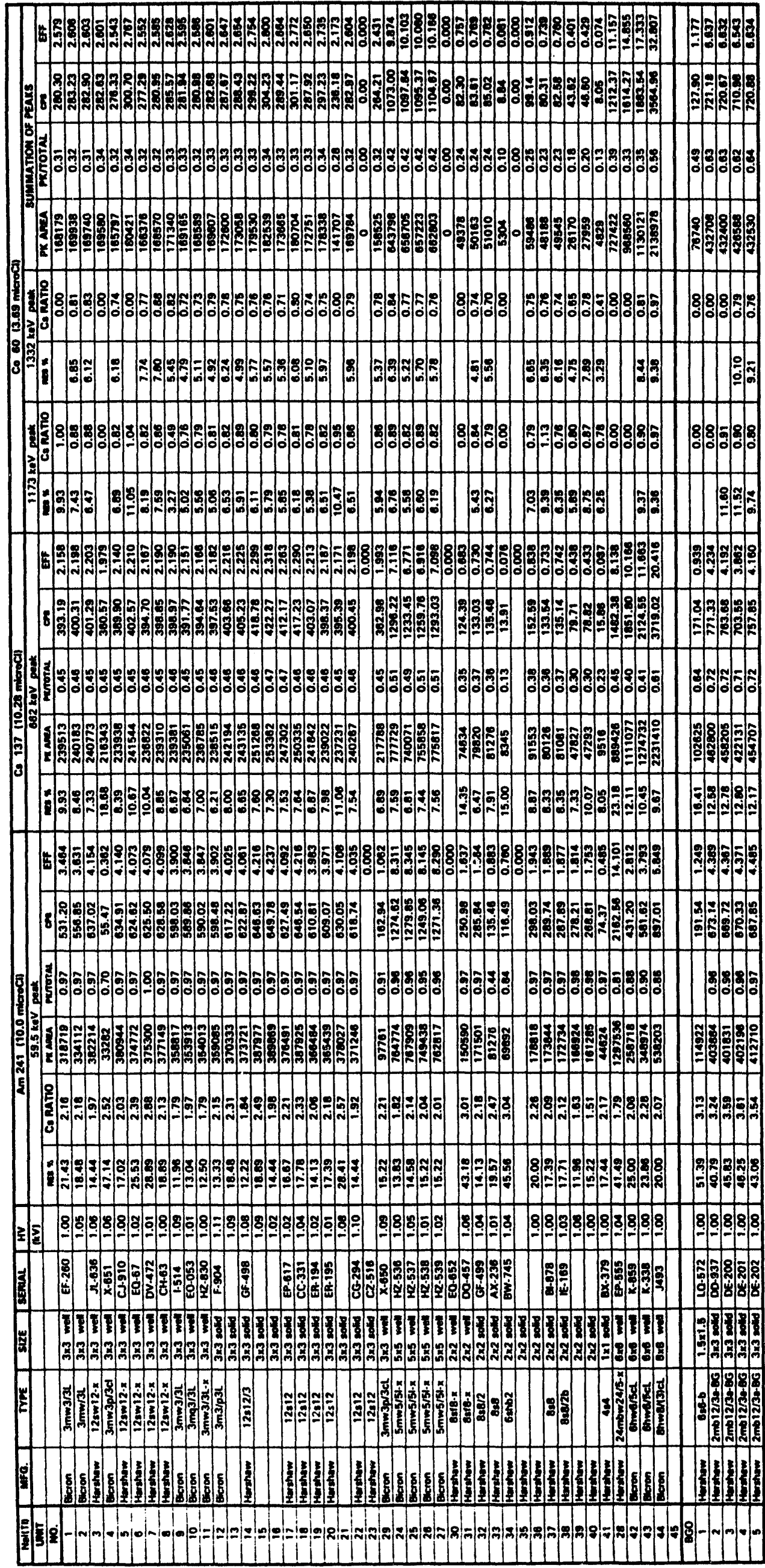

Appendix 3.3 

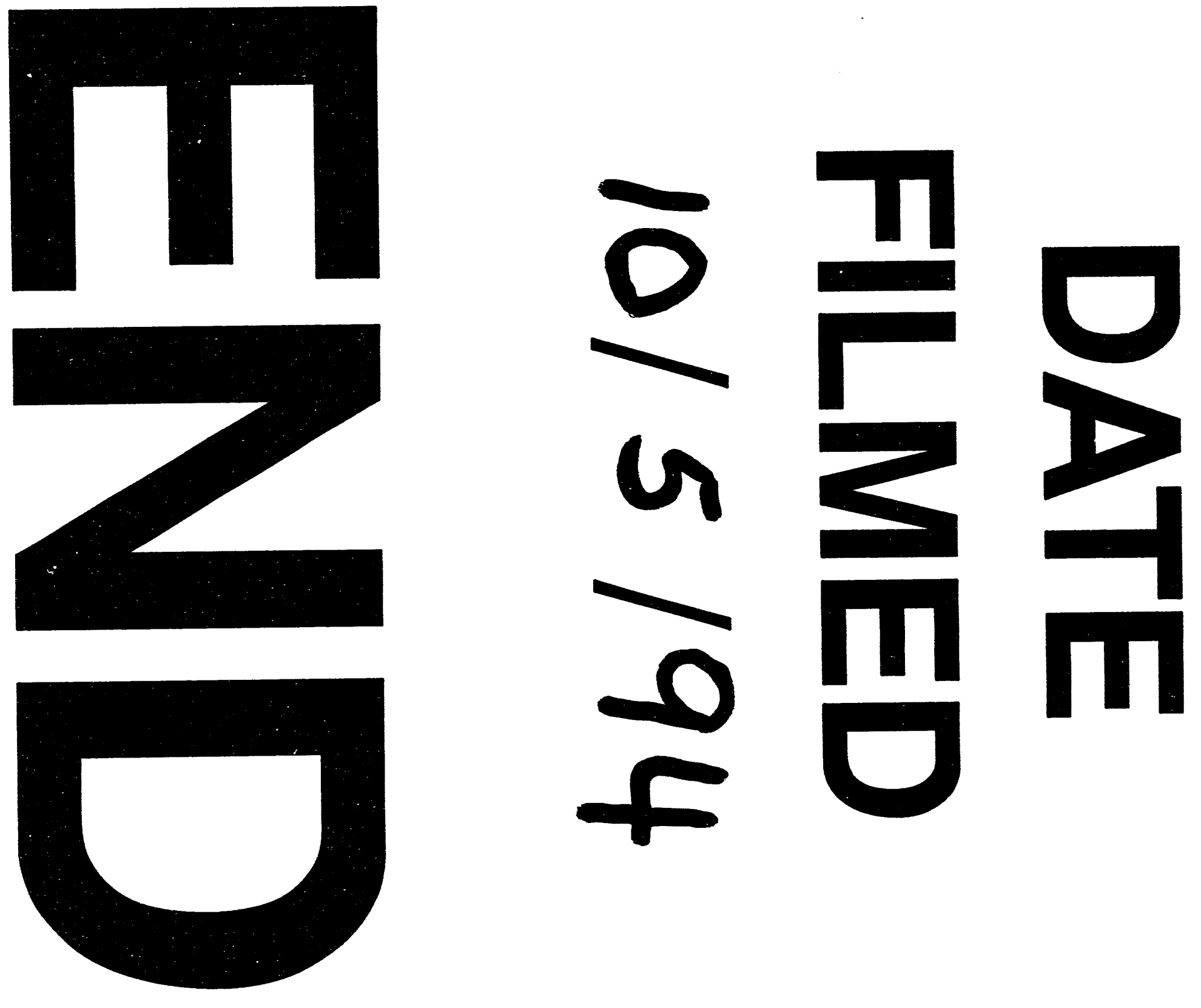


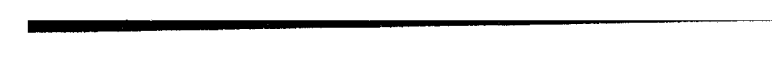

